OPEN ACCESS

Edited by:

Pushpa Pandiyan,

Case Western Reserve University,

USA

Reviewed by:

Wim Van Den Broeck,

Ghent University, Belgium

Charles Kelly,

King's College London, UK

*Correspondence:

Jeffrey L. Ebersole

jleber2@uky.edu

Specialty section:

This article was submitted to

Mucosal Immunity,

a section of the journal

Frontiers in Immunology

Received: 20 April 2016 Accepted: 28 June 2016

Published: 18 July 2016

Citation:

Ebersole JL, Kirakodu SS, Novak MJ,

Orraca L, Martinez JG,

Cunningham LL, Thomas MV,

Stromberg A, Pandruvada SN and Gonzalez OA (2016) Transcriptome Analysis of B Cell Immune Functions

in Periodontitis: Mucosal Tissue

Responses to the Oral Microbiome in

Aging.

Front. Immunol. 7:272.

doi: 10.3389/fimmu.2016.00272

\section{Transcriptome Analysis of B Cell Immune Functions in Periodontitis: Mucosal Tissue Responses to the Oral Microbiome in Aging}

\author{
Jeffrey L. Ebersole ${ }^{1,2 *}$, Sreenatha S. Kirakodu', M. John Novak', Luis Orraca ${ }^{3}$, Janis \\ Gonzalez Martinez ${ }^{3,4}$, Larry L. Cunningham ${ }^{4}$, Mark V. Thomas², Arnold Stromberg ${ }^{5}$, \\ Subramanya N. Pandruvada ${ }^{6}$ and Octavio A. Gonzalez ${ }^{1}$
}

${ }^{1}$ Center for Oral Health Research, College of Dentistry, University of Kentucky, Lexington, KY, USA, ${ }^{2}$ Division of Periodontics, College of Dentistry, University of Kentucky, Lexington, KY, USA, ${ }^{3}$ Caribbean Primate Research Center, Sabana Seca, PR, USA, ${ }^{4}$ Division of Oral and Maxillofacial Surgery, College of Dentistry, University of Kentucky, Lexington, KY, USA, ${ }^{5}$ Department of Statistics, College of Arts and Sciences, University of Kentucky, Lexington, KY, USA, ${ }^{6}$ Division of Orthodontics, College of Dentistry, University of Kentucky, Lexington, KY, USA

Evidence has shown activation of $\mathrm{T}$ and $\mathrm{B}$ cells in gingival tissues in experimental models and in humans diagnosed with periodontitis. The results of this adaptive immune response are noted both locally and systemically with antigenic specificity for an array of oral bacteria, including periodontopathic species, e.g., Porphyromonas gingivalis and Aggregatibacter actinomycetemcomitans. It has been recognized through epidemiological studies and clinical observations that the prevalence of periodontitis increases with age. This report describes our studies evaluating gingival tissue transcriptomes in humans and specifically exploiting the use of a non-human primate model of naturally occurring periodontitis to delineate gingival mucosal tissue gene expression profiles focusing on cells/genes critical for the development of humoral adaptive immune responses. Patterns of B cell and plasmacyte genes were altered in aging healthy gingival tissues. Substantial increases in a large number of genes reflecting antigen-dependent activation, B cell activation, B cell proliferation, and B cell differentiation/maturation were observed in periodontitis in adults and aged animals. Finally, evaluation of the relationship of these gene expression patterns with those of various tissue destructive molecules (MMP2, MMP9, CTSK, TNF $\alpha$, and RANKL) showed a greater frequency of positive correlations in healthy tissues versus periodontitis tissues, with only MMP9 correlations similar between the two tissue types. These results are consistent with $\mathrm{B}$ cell response activities in healthy tissues potentially contributing to muting the effects of the tissue destructive biomolecules, whereas with periodontitis this relationship is adversely affected and enabling a progression of tissue destructive events.

Keywords: B cells, periodontitis, aging, gingival tissues, non-human primates 


\section{INTRODUCTION}

"Negative, age-related changes in our innate and adaptive immune systems are known collectively as immunosenescence. A lifetime of stress on our bodies is thought to contribute to immunosenescence. Radiation, chemical exposure, and exposure to certain diseases can also speed up the deterioration of the immune system." This general concept conveyed by the National Institute of Aging has been supported by a wealth of epidemiological data, which has laid a foundation to better understand the age-related changes in immune functioning that facilitate increased development of an array of diseases later in life. Aging is a degenerative process with hallmarks of chronic inflammation and oxidative stressrelated mitochondrial damage that contribute to the initiation of other deleterious processes within cells, including epigenetic modification of gene expression that can affect normal cellular functions (1). Alterations in both innate and adaptive immunity have been universally observed in aging populations and have led to the birth of such terms as "immune-aging" or "immunosenescence" to reflect the deteriorating nature of the immune system (2). Studies have shown that increases in the incidence of inflammation, autoimmunity, cancer, and susceptibility to infections in aging individuals coincide with a significant decline in host immunity and can negatively affect the efficacy of vaccinations in the elderly $(3,4)$.

Age-related reductions in the adaptive immune response are often accompanied by the presentation of a chronic low-grade inflammatory state, termed "inflammaging," which can be influenced both by genetic and environmental factors and contributes to the individual variation observed within the population (5). Under normal circumstances, immunoactivation is a host defense response that evolved to protect humans against numerous pathogens. However, recent studies are showing that the coincident loss of normal innate and adaptive immune response capacity with aging, combined with low-grade chronic inflammation, work together to effectively alter immunocompetence and promote the pathogenesis of a diverse number of diseases (6). These findings suggest that "unhealthy" aging is driven in part by the dysregulation of immunoactivation (7). Alterations in positive and negative feedback signaling with aging appear to occur with all type of cells involved in immune responses; from short-lived neutrophils to long-lived $\mathrm{T}$ lymphocytes and macrophages. Recently, a review by Boraschi et al. (8) summarized several possible causes of immunosenescence and provided some strategies for counteracting this decline of immune responsiveness with aging.

Animal models, frequently focusing on the use of various genetically unique strains of laboratory mice, have been employed to advance our knowledge of aging and will continue to be useful tools. These types of studies can address many of the basic questions pertaining to the molecular regulation and/ or dysregulation of the immune response and increased inflammation that accompanies aging. More recent studies have utilized

\footnotetext{
${ }^{1}$ http://www.nia.nih.gov/health/publication/biology-aging/immune-system-canyour-immune-system-still-defend-you-you-age
}

these approaches in rodents to examine the impact of aging on periodontitis, and generally supported an increase in disease with aging (9-11). However, there are many fundamental differences in the basic immunology of mice and humans, particularly with respect to the microbiome composition, characteristics of immune cell transcriptional regulators, and receptors utilized for engaging pathogens and commensal bacteria, as well as the types of environmental stressors. Moreover, the rodent model has generally focused on the potential role of individual molecules within complex pathways in attempting to explain susceptibility or resistance to disease (12-16). These studies generally do not address the biology of the system that will be necessary to clearly define the multivariate changes that occur with healthy and diseased aging (2). Thus, Franceschi et al. (17) have proposed a "network theory of aging" emphasizing a broad reduction in the ability of the host response systems to cope with the array of challenges in concert with a progressing intrinsic proinflammatory environment that accompanies the aging process. These concepts emphasize a remaining need for sophisticated and detailed documentation of the human or human-like models of aging and immunosenescence (17).

While substantial emphasis has been placed on studies of innate immune and inflammatory responses in chronic periodontitis over the decades (18), extensive findings have described local and systemic antibody responses that (i) react with certain bacteria (19-21), (ii) increase with periodontitis, and (iii) are altered by treatment (22). Examination of the gingival tissue transcriptome in various studies have either "cast a broad net" to identify the multitude of differences between health and disease (23-27) or focused on innate immune response molecules (28-31). This article describes our ongoing studies focusing on the use of a nonhuman primate model of periodontitis to explore the response environment in the gingival mucosal tissues. We spotlight in this report on cellular markers of humoral adaptive immunity related to aging and chronic inflammatory disease of the oral mucosa and alveolar bone.

Various discussions regarding the role of adaptive immunity, and particularly humoral immune responses in the development of, or protection from, periodontitis have occurred over the decades, with some consistency in findings regarding antibody levels increased with disease $(20,22)$; however, severe generalized disease may show some decreased antibody levels (32-35). Treatment of periodontal disease usually associated with early increases but long-term decreases with successful therapy in antibody specific for oral bacteria (36-40). Animals models have also demonstrated the potential for antigen-specific $\mathrm{T}$ and $\mathrm{B}$ cells to exacerbate local disease (41-43), whereas active immunization has demonstrated protection from induced disease $(16,44-47)$.

\section{MATERIALS AND METHODS}

\section{Human Gingival Samples}

Gingival tissue samples were obtained from three healthy and four periodontitis patients following Institutional Review Board approval and patient consent to utilize discarded tissues from standard of care surgical therapy for periodontitis and impacted 
third molar removal. Healthy tissues were uninflamed obtained from third molar extractions, patients aged 25-36 years, 66\% females. The periodontitis samples were obtained via surgical therapy from sites with pocket depth $\geq 6 \mathrm{~mm}$ and radiographic evidence of alveolar bone loss, aged 32-51 years, 50\% females. The samples were obtained and placed into chilled buffer. Total RNA was isolated from each gingival tissue specimen using TRIzol reagent following the protocol recommended by the manufacturer (Invitrogen, Indianapolis, IN, USA). The extracted RNA was cleaned up using the Qiagen RNeasy mini kit (Qiagen, Valencia, CA, USA) and quantified using spectrophotometric analysis. RNA from each sample was reverse transcribed and hybridized to the GeneChip ${ }^{\circledR}$ HT Human Genome U133 Plus 2.0 Array (Affymetrix, Santa Clara, CA, USA) similar to methods we have described previously. Probe arrays were scanned using GeneChip Scanner 3000 for high resolution scanning and GeneChip Operating Software MAS 5.0.

\section{Non-Human Primate Experimental Design}

Rhesus monkeys (Macaca mulatta) $(n=34 ; 14$ females and 20 males) housed at the Caribbean Primate Research Center (CPRC) at Sabana Seca, PR, USA, were used in these studies. A crosssectional study of healthy and naturally occurring periodontitis (48) animals were categorized as: young healthy ( $\leq 3$ years; $n=5$ ), adolescent healthy ( $3-7$ years; $n=5)$, adults ( $12-16$ years) healthy $(n=7)$ and periodontitis $(n=5)$, and aged (18-23 years) healthy $(n=6)$ and periodontitis $(n=6)$. The non-human primates were typically fed a $20 \%$ protein, $5 \%$ fat, and $10 \%$ fiber commercial monkey diet (diet 8773, Teklad NIB primate diet modified: Harlan Teklad). The diet was supplemented with fruits and vegetables, and water was provided ad libitum in an enclosed corral setting.

A protocol approved by the Institutional Animal Care and Use Committee (IACUC) of the University of Puerto Rico, enabled anesthetized animals to be examined for clinical measures of periodontal health, including probing pocket depth (PPD), and bleeding on probing (BOP) as we have described previously (49). Naturally occurring periodontitis sites were defined as PPD $\geq 4 \mathrm{~mm}$ and $\mathrm{BOP} \geq 1$.

\section{Microarray Analyses}

A buccal gingival sample from either healthy or periodontitisaffected tissue from the premolar/molar maxillary region of each animal was taken using a standard gingivectomy technique, and maintained frozen in RNAlater solution. Total RNA was isolated from each gingival tissue using a standard procedure as we have described, and tissue RNA samples submitted to the microarray core to assess RNA quality analyze the transcriptome using the GeneChip ${ }^{\circledR}$ Rhesus Macaque Genome Array (Affymetrix) $(48,50)$. Individual samples were used for gene expression analyses.

\section{Statistical Analyses}

Normalization of values across the chips was accomplished through signal intensity standardization across each chip using Affymetrix PLIER algorithm. The arrays contained matched and mismatched pairs allowing the MAS 5 algorithm to be used. For each gene, we first determined differences in expression across the groups using ANOVA (Version 9.3, SAS Inc., Cary, NC, USA). The healthy aged tissues were then compared with the other age groups using a $t$-test and accepting a $p$-value $\leq 0.05$ for significance. Because of the cost of these types of non-human primate experiments and availability of primates of the various ages, we did not have sufficient samples to identify if the relationship between age and gene expression could be treated using a linear model; thus, the subjects were classified, and ANOVA was used for analysis. The choice of Least Significant Difference for multiple comparisons (ANOVA followed by $t$-tests) provided maximum power given our necessarily small sample sizes. We determined a correlation with aging in healthy tissues using a Spearman Rank correlation analysis that was fit to the gene expression by age. A $p$-value $\leq 0.05$ was used to evaluate the significance of the correlation. Volcano plots were prepared to visualize outlier gene expression profiles in the aging animals compared with the other age group (51). The heat maps with hierarchical clusters were prepared using $\mathrm{MeV}$ 4_9_0 (open source genomic analysis software). ${ }^{2}$ These data have been uploaded into the ArrayExpress data base ${ }^{3}$ under accession number: E-MTAB-1977.

\section{RESULTS}

\section{Gingival Transcriptome Alterations in Aging and Periodontitis}

While reports have documented the end result of adaptive immune cell functions, i.e., antibody, rather sparse information is available regarding the cellular changes that occur in the periodontitis gingival tissues with respect to the adaptive immune response. Figure 1 provides volcano plots depicting the characteristics of gene expression differences in healthy and naturally occurring periodontitis tissues from humans and non-human primates. This profile provides a depiction of the magnitude of change in each gene (i.e., Fold $\Delta$ ) and the level of significant difference (i.e., $p$-value) in each gene comparing periodontitis to healthy tissues. Table 1 summarizes the identification of the top 50 upregulated genes in periodontitis gingival tissues from humans and non-human primates compared with healthy gingiva. The interesting aspect of these findings was that of the top 50 upregulated expressed genes in periodontitis tissues from humans and the non-human primates $40-60 \%$ were representative of genes that would affect the adaptive immune response including antigen presentation and processing, B and $\mathrm{T}$ cell regulation, and regulation of immunoglobulin characteristics. These findings support an active role in the complex gingival environment of established periodontitis lesions for the adaptive immune response. Whether this response profile is a hallmark for the development and expression of a protective immune response remains unclear in human disease (20, $22,52)$. Furthermore, the effects of aging on these patterns of responses remain understudied.

\footnotetext{
${ }^{2}$ www.tm4.org

${ }^{3}$ www.ebi.ac.uk
} 
A

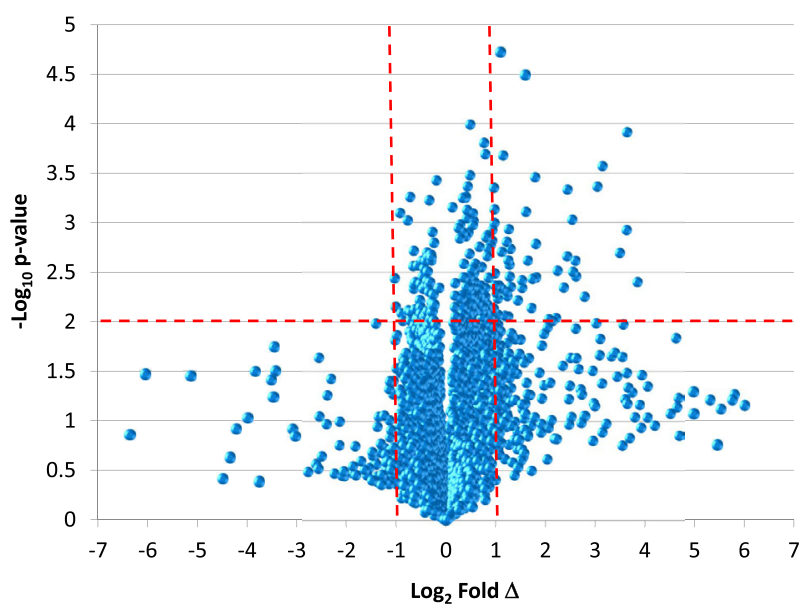

B

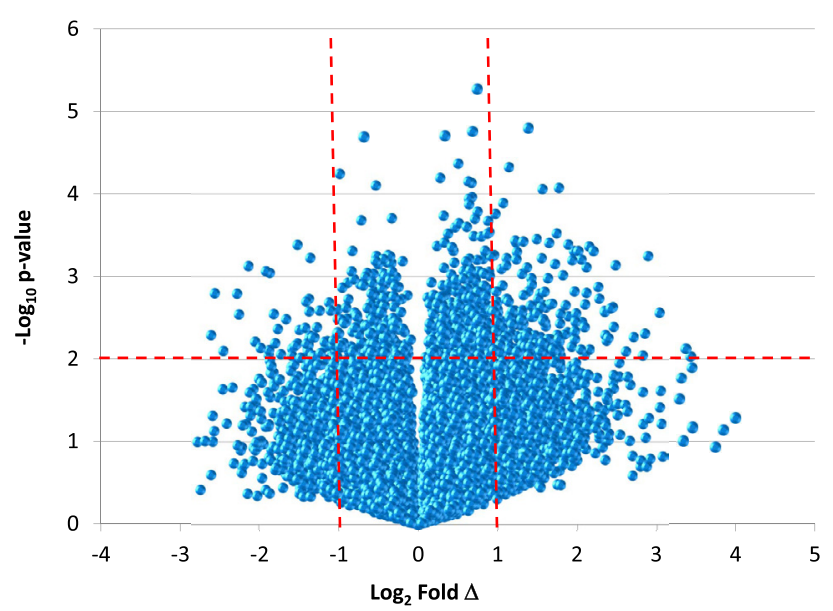

FIGURE 1 | Volcano plots of gene expression in human gingival tissues (A) and non-human primate gingival tissues (B) comparing levels in periodontitis tissues from healthy tissues. Human samples ( $n=3$ healthy; $n=4$ periodontitis) and non-human primate samples $[n=13$ healthy; $n=11$ periodontitis (adults and aged)] were tested. The graphs displays a point for the expression of each gene in periodontitis versus healthy tissues plotted as log ${ }_{2}$ fold difference $(\Delta)$ and $-\log _{10} p$-value significance versus healthy tissues. The vertical red dashed lines signify a fold difference in expression at twofold and the horizontal red dashed line signifies a significant difference of $p<0.01$.

\section{B Cell- and Plasmacyte-Associated Transcriptome in Aging and Periodontitis}

To evaluate alterations in B cell development and maturation in the gingival tissue, we documented expression of 190 genes that are associated with B cell and plasmacyte development and functions. We also categorized the B cell genes into those related to $B$ cell activation, proliferation, and differentiation, as well as antigen-stimulated activation of these cells. The plasmacyte genes were related to general cellular expression and those suggested to be altered in early or mature plasmacytes. Figure $\mathbf{2 A}$ is a diagrammatic representation of altered gene expression profiles in healthy gingival tissues from young, adolescent, and aged animals compared with levels in healthy adult tissues. The results show that 31 genes are expressed at higher levels in the healthy aged tissues, whereas only 1 and 5 were elevated in young and adolescent healthy gingiva compared with healthy adult tissues. The figure also demonstrates that all gene changes in the young and adolescent overlapped with the changes in aged tissues. In contrast, only 2 of this gene set were downregulated in healthy aging tissues, whereas 19 were significantly decreased in young and 15 in adolescent tissues with approximately $50 \%$ overlapping. Figure 2B presents an overview of the prevalence of genes that were up- or downregulated in periodontitis in the adult or aged animals (naturally occurring periodontitis does not present in the younger animal groups). The results showed that two times more genes were upregulated in aged periodontitis tissues compared with the adult group. Approximately $90 \%$ of the elevated genes in adult periodontitis tissues were also elevated in the aging tissues. In contrast, very few genes were downregulated with periodontitis in either age group, with only about $1 / 2$ of these genes overlapping in the two age groups.
We then examined the characteristics of these altered genes related to B cell functions. Table 2 summarizes these alterations in healthy tissues of each of the age groups compared with levels in healthy adult tissues. The majority of gene expression changes in the healthy tissues were associated with antigen-dependent activation and B cell differentiation/maturation processes (26.3 and $37.9 \%$, respectively). As was noted in the Venn diagrams, the majority of the gene changes were elevations in aged healthy tissues across all functional groups.

Figures $\mathbf{3 A - G}$ provide the results of gene expression changes in the various functional categories related to periodontitis in adults and aged animals, as well as a summary of all periodontitis samples. With the antigen-dependent activation genes, 21 out of 38 were altered with periodontitis, generally being increased in both age groups, and most often with fold increases greatest in the aged group. Only CD274 (programed death-ligand 1 with a major role in suppressing the immune system through a signal that inhibits TCR-mediated activation of IL-2 production and T cell proliferation) and ID3 (DNA-binding protein inhibitor ID-3 is a transcription inhibitor) were decreased with periodontitis. $\mathrm{B}$ cell activation genes were altered $(8 / 18)$ with periodontitis, again showing higher fold increases in the aged tissues. Approximately 14/33 B cell proliferation-related genes were altered with periodontitis in both adults and aged animals. Of these, only BCL2L1 (potent inhibitor of cell death by inhibiting activation of caspases) and FLT3 (Fms-like tyrosine kinase 3 or CD135 is important or lymphocyte development) were consistently decreased. Examination of the $\mathrm{B}$ cell differentiation/maturation genes showed 32/58 were altered in periodontitis (Figures 3D,E). Again the highest fold increases were in the aged tissue samples. Interestingly, one-third of these genes were associated with genes 
TABLE 1 | Identification of the top 50 upregulated genes in periodontitis versus healthy gingival tissues related to adaptive immune responses.

\begin{tabular}{|c|c|c|c|}
\hline \multicolumn{2}{|c|}{ Human } & \multicolumn{2}{|c|}{ Non-human primate } \\
\hline Gene ID & $r(i)$ & Gene ID & $r(i)$ \\
\hline V-DXP4-JH6c & 24.7 & |GHV-II| VH26 & 10.29 \\
\hline IGKVJ & 14.39 & IGHV-II SESS & 8.87 \\
\hline IGVH1 & 12.43 & VPREB2 & 8.64 \\
\hline V-DK4-JH4b & 12.33 & IGKV-1 HK102 & 8.49 \\
\hline C-D-JH6 & 11.84 & IGKV-11 RPMI6410 & 7.69 \\
\hline IGL & 11.22 & CD179b & 7.57 \\
\hline IGK-3D-15 & 8.6 & IGKV-1 HK101 & 6.17 \\
\hline IGLV2-23*01 & 8.2 & KLRC1 & 6.16 \\
\hline MUC5AC & 8.08 & MMP3 & 5.81 \\
\hline NHPHL7 & 6.9 & IGHV4-1 & 5.75 \\
\hline SCYB6 & 6.16 & IGLV-I BL2 & 5.73 \\
\hline GRO1 & 6.1 & ZLG & 5.49 \\
\hline IGLJ3 & 6.03 & PIP & 5.41 \\
\hline TMEM156 & 5.89 & IGLV-II MGC & 5.2 \\
\hline IGHG3 & 5.78 & IGHA2 & 5.19 \\
\hline PABL & 5.42 & FAM123A & 5 \\
\hline KYNU & 5.4 & CLDN8 & 4.75 \\
\hline IL8 & 5.15 & |GLV-III LOI & 4.73 \\
\hline UBD & 4.71 & $\mathrm{IGH}$ & 4.44 \\
\hline VNN1 & 4.62 & IGJ & 4.39 \\
\hline SLU7 & 4.19 & ADCYAP1 & 4.37 \\
\hline IGKVJ & 4.11 & TVB2 CTL-L17 & 4.35 \\
\hline IGVH4 & 3.9 & IGHV-II ARH-77 & 4.26 \\
\hline CPD & 3.79 & IGHV & 4.26 \\
\hline PLAC8 & 3.51 & POU2AF1 & 4.25 \\
\hline IGKVJC & 3.49 & APOE & 4.23 \\
\hline SOD2 & 3.45 & MCART6 & 4.15 \\
\hline IGK & 3.34 & IL19 & 4.13 \\
\hline IGLP3 & 3.27 & hmRNPA1 & 4.12 \\
\hline CASP3 & 3.11 & CXCL1 & 4.05 \\
\hline MS4A2 & 3.06 & CCL20 & 4.05 \\
\hline CD20 & 3 & IGLL1 & 4.04 \\
\hline MDM4 & 2.89 & KLRF1 & 3.87 \\
\hline PLAT & 2.87 & COX6C & 3.75 \\
\hline GLDC & 2.81 & HLA-DOB & 3.7 \\
\hline CEACAM1 & 2.71 & FAM30A & 3.64 \\
\hline YES1 & 2.62 & FOSB & 3.57 \\
\hline PTH & 2.53 & CENPT & 3.53 \\
\hline XBP1 & 2.49 & SPATA4 & 3.52 \\
\hline FMO2 & 2.47 & FAM46C & 3.49 \\
\hline SOD2 & 2.45 & IGL & 3.43 \\
\hline PSME4 & 2.44 & SPAST & 3.39 \\
\hline SLC1A1 & 2.41 & IGHG1 & 3.39 \\
\hline C20orf67 & 2.38 & TNNI2 & 3.38 \\
\hline HS3ST1 & 2.38 & LILRA1 & 3.38 \\
\hline CLCA4 & 2.34 & IGLV-I| BUR & 3.38 \\
\hline GPR65 & 2.34 & BANK1 & 3.37 \\
\hline PHLDA1 & 2.33 & IGHV-I V35 & 3.36 \\
\hline HSP13A & 2.16 & IRF4 & 3.27 \\
\hline SLP76 & 2.15 & TACl & 3.27 \\
\hline IGA1C & 2.13 & IGK & 3.26 \\
\hline
\end{tabular}

Genes highlighted in yellow associated with adaptive immune responses.

related to immunoglobulin heavy and light change rearrangement and production. Only 6/25 plasmacyte-related genes were altered with periodontitis with all being increased in both adult and aged animals. Finally, a group of genes with multiple functions in humoral immune responses are presented (Figure 3G) with $8 / 17$ being altered, and only IL4 being consistently decreased in adult and aged periodontitis tissues.
Figure 4 provides a heatmap of the clustering of the B cell/ plasmacyte genes in healthy and periodontitis samples from adults and aged animals. The results provide a visualization of a cluster of genes that are clearly elevated in expression in healthy aged tissues and then increase substantially in periodontitis or more specifically, only in aged periodontitis tissues. Table 3 provides a summary of these gene expression changes identified with their primary gene functions. Six of the 26 gene alterations were related to antigen-dependent stimulation of the B cells, generally increasing sequentially from adult to aged healthy tissues and then continuing increased with adult to aged periodontitis tissues. The majority of changes were associated with differentiation/ maturation functions, particularly related to immunoglobulin diversity. The changes were noticeable in that the fold-increase approximately doubled from adult to aged healthy, and then the changes were threefold to sevenfold increased comparing healthy adult to periodontitis or healthy aged to periodontitis.

Since host-induced tissue destruction is a feature of the chronic inflammation of periodontitis, we explored the relationship between gingival expression of the B cell/plasmacyte group of genes and expression of genes associated with periodontal tissue destruction during health and periodontal disease irrespective of age. Included in these tissue destructive responses were evaluation of MMP2 (72 kDa type IV collagenase or gelatinase A active in extracellular matrix degradation and effects on integrins), MMP9 (92 kDa type IV collagenase or gelatinase $\mathrm{B}$, a regulatory factor in neutrophil migration and functions), CTSK (a lysosomal cysteine protease involved in bone remodeling and resorption, can catabolize elastin, collagen, and gelatin), TNF (tumor necrosis factor alpha or cachexin is a cell signaling protein involved in systemic inflammation and contributes to the acute phase response with cell cytotoxic capabilities), and RANKL (receptor activator of nuclear factor kappa-B ligand also TNFSF11 is a principal factor in osteoimmunology linking the immune system and bone biology, as well as an apoptosis regulatory gene). The heatmap shows the correlations in either healthy or periodontitis samples of the B cell genes with the expression of tissue destructive genes (Figure 5) and provides an overview of the correlation of the B cell/plasmacyte genes with the five tissue destructive genes in healthy and periodontitis tissues (adult and aged combined). Cluster 1 contained 15 genes showing a positive correlation with $\mathrm{TNF} \alpha$ and negative correlation with MMP9, primarily in the periodontitis tissues. Cluster 2 genes $(n=12)$ were positively correlated with the expression of MMP2 and CTSK in both health and periodontitis, as well as with MMP9 only in periodontitis. Cluster 3 was a subset with 14 genes that negatively correlated with MMP2 in healthy samples and positively correlated with MMP9, RANKL, and CTSK in only the periodontitis samples. Cluster 4 contained 10 genes that were positively correlated with both MMP9 and CTSK in periodontitis. Cluster 5 genes $(n=34)$ showed a positive correlation with MMP9, RANKL, and CTSK in both healthy and periodontitis tissues, and a positive correlation with TNF $\alpha$, but only in the healthy tissues. Cluster 6 contained 34 genes with strong positive correlations with MMP9 and CTSK in both healthy and periodontitis tissues, and a negative correlation with TNF $\alpha$ in periodontitis. Cluster 7 grouped 28 genes with positive correlations to RANKL only in periodontitis tissues, 


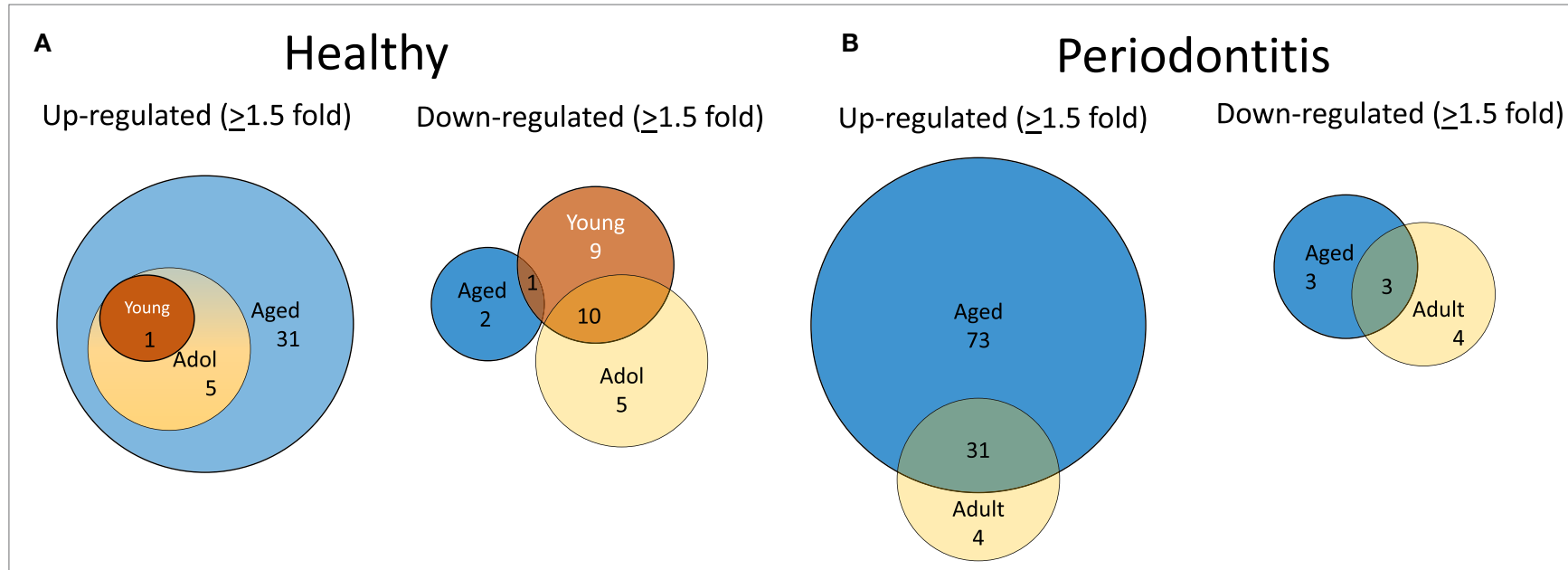

FIGURE 2 | Venn diagram depicting altered gene expression in healthy tissues (A) and periodontitis tissues (B) compared with levels in healthy adult tissues. Gene numbers denote fold differences by $\geq 1.5$-fold. Naturally occurring periodontitis does not occur in younger age groups.

TABLE 2 | Alterations in gene expression in healthy gingival tissues related to gene functional categories.

\begin{tabular}{|c|c|c|c|c|c|c|c|c|}
\hline \multirow[t]{3}{*}{ Gene functions } & \multirow{3}{*}{$\begin{array}{l}\text { Total } \\
\text { genes }\end{array}$} & \multicolumn{7}{|c|}{ Altered gene expression } \\
\hline & & \multirow{2}{*}{$\begin{array}{l}\text { Total } \\
\uparrow \text { or } \downarrow\end{array}$} & \multicolumn{2}{|c|}{ Young } & \multicolumn{2}{|c|}{ Adolescent } & \multicolumn{2}{|c|}{ Aged } \\
\hline & & & $\uparrow$ & $\downarrow$ & $\uparrow$ & $\downarrow$ & $\uparrow$ & $\downarrow$ \\
\hline $\begin{array}{l}\text { Antigen-dependent } \\
\text { activation }\end{array}$ & 38 & 10 & 0 & 6 & 1 & 3 & 8 & 0 \\
\hline B cell activation & 18 & 4 & 0 & 1 & 0 & 0 & 3 & 3 \\
\hline B cell proliferation & 33 & 6 & 0 & 2 & 0 & 2 & 5 & 0 \\
\hline $\begin{array}{l}\text { Differentiation/ } \\
\text { maturation }\end{array}$ & 58 & 22 & 1 & 8 & 4 & 9 & 18 & 1 \\
\hline Plasmacyte & 25 & 2 & 0 & 1 & 0 & 2 & 1 & 0 \\
\hline Multiple functions & 17 & 3 & 0 & 2 & 0 & 2 & 1 & 0 \\
\hline
\end{tabular}

$\uparrow$ or $\downarrow$ denotes gene expression that was up- or downregulated compared with healthy adult tissues.

and strong negative correlations to CTSK in periodontitis and MMP2 in both healthy and periodontitis samples. Cluster 8 genes $(n=18)$ were similar to cluster 7 with negative correlations to MMP2 and CTSK in periodontitis and health, as well as negative correlations with MMP9 in periodontitis tissues. Finally, cluster 9 genes $(n=8)$ were similar to expression patterns for cluster 8 , except for positive correlations with TNF $\alpha$ in periodontitis.

Table 4 summarizes the distribution of functional categories of the genes in each of these clusters and demonstrates some skewing of gene functions related to the various clusters of association with tissue destructive gene expression profiles. Clusters 1, 4, and 8 showed an expected general distribution across the functions. Cluster 3 showed an increased frequency of differentiation/maturation genes and decreased plasmacyte expression profiles. Clusters 4, 5, and 7 all exhibited increased proportions of the multiple function B cell genes. Cluster 6 was enriched for non-antigen-dependent B cell activation genes, whereas cluster 7 was depleted in this gene function. Finally, cluster 9 , while containing a low number of genes was enriched for B cell proliferation genes, while being decreased for differentiation/maturation genes.

\section{DISCUSSION}

Dysregulation of multiple components of the immune system with aging contributes to increased prevalence and severity of infections and poses a challenge for prevention of infectious diseases via effective vaccination in aging populations. These dysfunctions have been described for adaptive immune B and T cells. Thus, aging individuals' exhibit increased susceptibility to a number of inflammatory and degenerative pathologies. Included in this listing is an increased prevalence and severity of periodontitis, although the underlying causes remain poorly understood. The effects of aging on periodontal tissues have been suggested to be based on molecular changes in the array of cells of the periodontium, the combination of which is thought to intensify alveolar bone resorption in elderly individuals. These effects are considered to be reflective of (1) altered differentiation/ proliferation of cells for uncoupling bone biological processes (osteoblasts, osteoclasts); (2) enhanced responses to the oral microbiota, modified by environmental stressors leading to the secretion of cytokines/chemokines involved in osseous resorption; and (3) systemic endocrine alterations related to host responses and physiologic/pathologic bone responses with aging (53-56). Hajishengallis (57) proposed that an impaired modulation of the innate immune and inflammatory capacity of the host could also be associated with aging-related periodontitis. Nevertheless, less attention has been placed on the potential role of aging-related adaptive immunity changes that could be contributing to higher incidence and severity of periodontitis with aging. In general, most of the evidence is supported by studies demonstrating that innate immune and adaptive immune cells isolated from aged individuals exhibit intrinsic defects that could predispose the elderly to dysregulated immune and inflammatory responses underpinning the exacerbated clinical features of disease with 


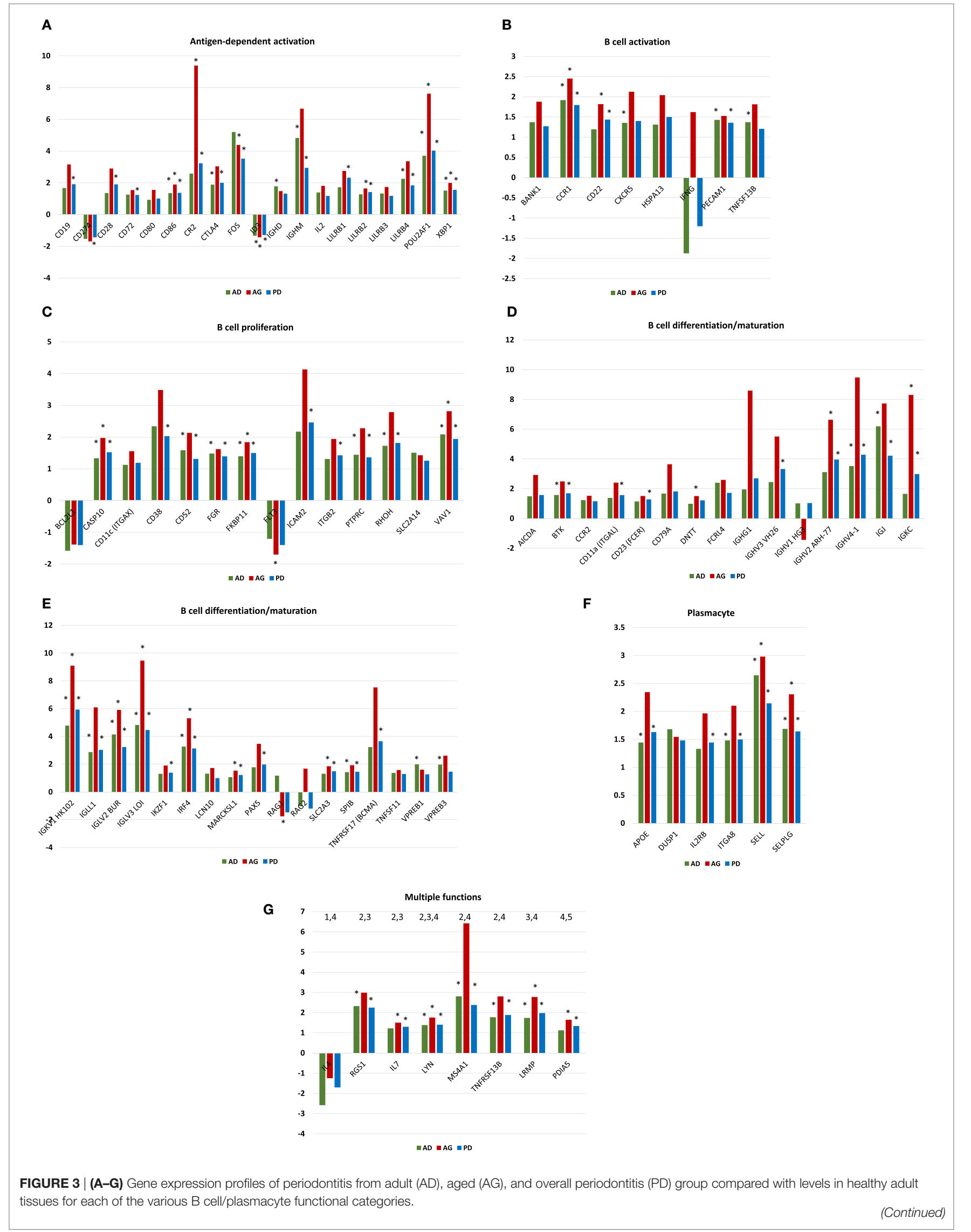




\section{FIGURE 3 | Continued}

The bars denote the mean fold difference of disease from health. Only those genes with a fold difference $\geq 1.5$ or $\leq-1.5$ in any of the three comparisons were included in the graph (21/38). The asterisk defines comparisons that were significantly different at least at $p<0.05$.

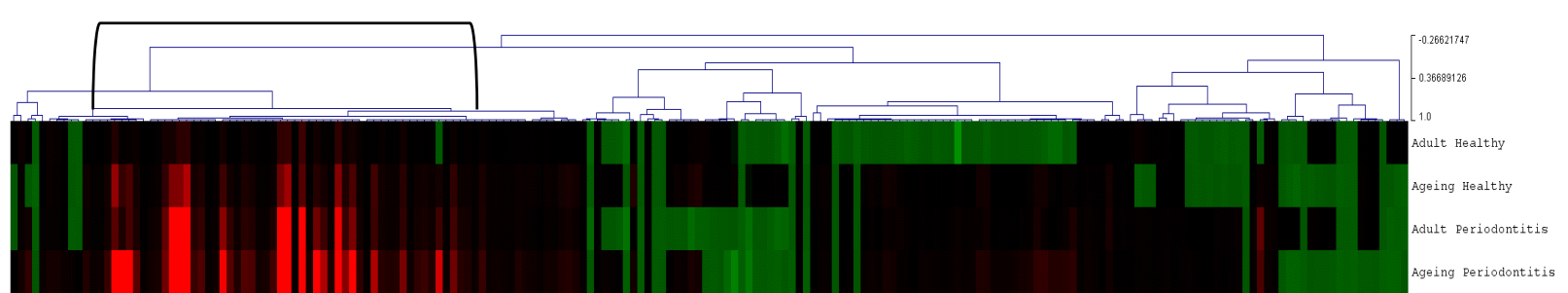

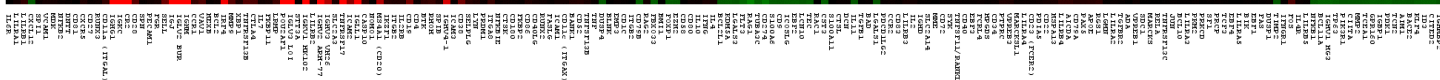

FIGURE 4 | Heatmap of fold differences in gene expression in adult and aged healthy and periodontitis tissues compared with response levels in healthy gingival tissues from a group of $\mathbf{1 0}$ animals 3-7 years of age (approximately 11- to 25-year-old humans). The bracket identifies a cluster of genes that were highly expressed in adult and aged tissues, particularly with periodontitis.

TABLE 3 | Gene expression differences in adult and aged healthy and periodontitis tissues related to average gene response patterns in healthy tissue samples from animals 3-7 years of age (correlates with 11- to 25-year-old human).

\begin{tabular}{|c|c|c|c|c|c|}
\hline \multirow[b]{2}{*}{ Gene ID } & \multicolumn{4}{|c|}{ Fold difference } & \multirow[b]{2}{*}{ Fxn. Category } \\
\hline & Adult H & Aged H & Adult PD & Aged PD & \\
\hline CCR1 & 1.2 & 1.8 & 2.4 & 3.1 & 2 \\
\hline CD19 & 1.7 & 2.5 & 2.8 & 5.2 & 1 \\
\hline CD28 & 1.5 & 1.8 & 2.0 & 4.3 & 1 \\
\hline CD20 (MS4A1) & 1.1 & 3.3 & 3.2 & 7.3 & 2.4 \\
\hline CR2 (CD21) & 1.4 & 3.7 & 3.5 & 12.8 & 1 \\
\hline CTLA4 & 1.2 & 1.8 & 2.3 & 3.8 & 1 \\
\hline FOS & 0.8 & 1.5 & 4.4 & 3.7 & 1 \\
\hline ICAM2 & 1.1 & 1.4 & 1.3 & 1.7 & 3 \\
\hline $\mid \mathrm{GHG} 1$ & 2.2 & 6.3 & 4.2 & 18.5 & 4 \\
\hline IGHM & 2.5 & 7.4 & 12.2 & 16.9 & 4 \\
\hline IGHV2 ARH-77 & 1.6 & 2.4 & 5.1 & 10.8 & 4 \\
\hline IGHV3 VH26 & 1.3 & 1.8 & 3.2 & 7.1 & 4 \\
\hline IGHV4-1 & 0.9 & 1.8 & 3.2 & 8.5 & 4 \\
\hline IGJ & 2.4 & 5.5 & 14.9 & 18.6 & 4 \\
\hline IGKC & 1.3 & 2.9 & 2.1 & 10.4 & 4 \\
\hline IGKV1 HK102 & 3.1 & 4.1 & 14.6 & 27.9 & 4 \\
\hline IGLV2 BUR & 2.6 & 5.5 & 10.9 & 15.5 & 4 \\
\hline IGLV3 LOI & 3.0 & 6.7 & 14.6 & 28.7 & 4 \\
\hline IGLL1 & 1.9 & 3.7 & 5.4 & 11.5 & 4 \\
\hline IRF4 & 1.8 & 3.2 & 6.0 & 9.7 & 4 \\
\hline LRMP & 1.2 & 1.5 & 2.1 & 3.3 & 3.4 \\
\hline POU2AF1 & 2.8 & 5.1 & 10.4 & 21.4 & 1 \\
\hline SELL & 1.7 & 2.7 & 4.4 & 5.0 & 5 \\
\hline TNFRSF13B & 1.4 & 2.1 & 2.5 & 4.0 & 2.4 \\
\hline TNFRSF17 & 3.0 & 5.8 & 9.6 & 22.3 & 4 \\
\hline VAV1 & 1.4 & 2.1 & 2.9 & 4.0 & 3 \\
\hline
\end{tabular}

aFunctional categories denoted as 1 - antigen-dependent activation; 2 - cell activation; 3 - cell proliferation; 4 - differentiation/maturation; 5 - plasmacyte; 6 - multiple functions.

aging. Integrated approaches examining cellular biology, animal models, and human studies of aging should contribute to targeted molecular therapies that could mitigate the initiation and progression of periodontitis in aging and/or reverse the effects of aging on periodontitis as a chronic inflammatory disease.
The literature has clearly described the characteristics of the humoral adaptive immune response across gingival health toward various forms of periodontal disease with immunoglobulins (antibodies) of all isotypes generally present at low levels in gingival crevicular fluid from healthy sites, minimizing 


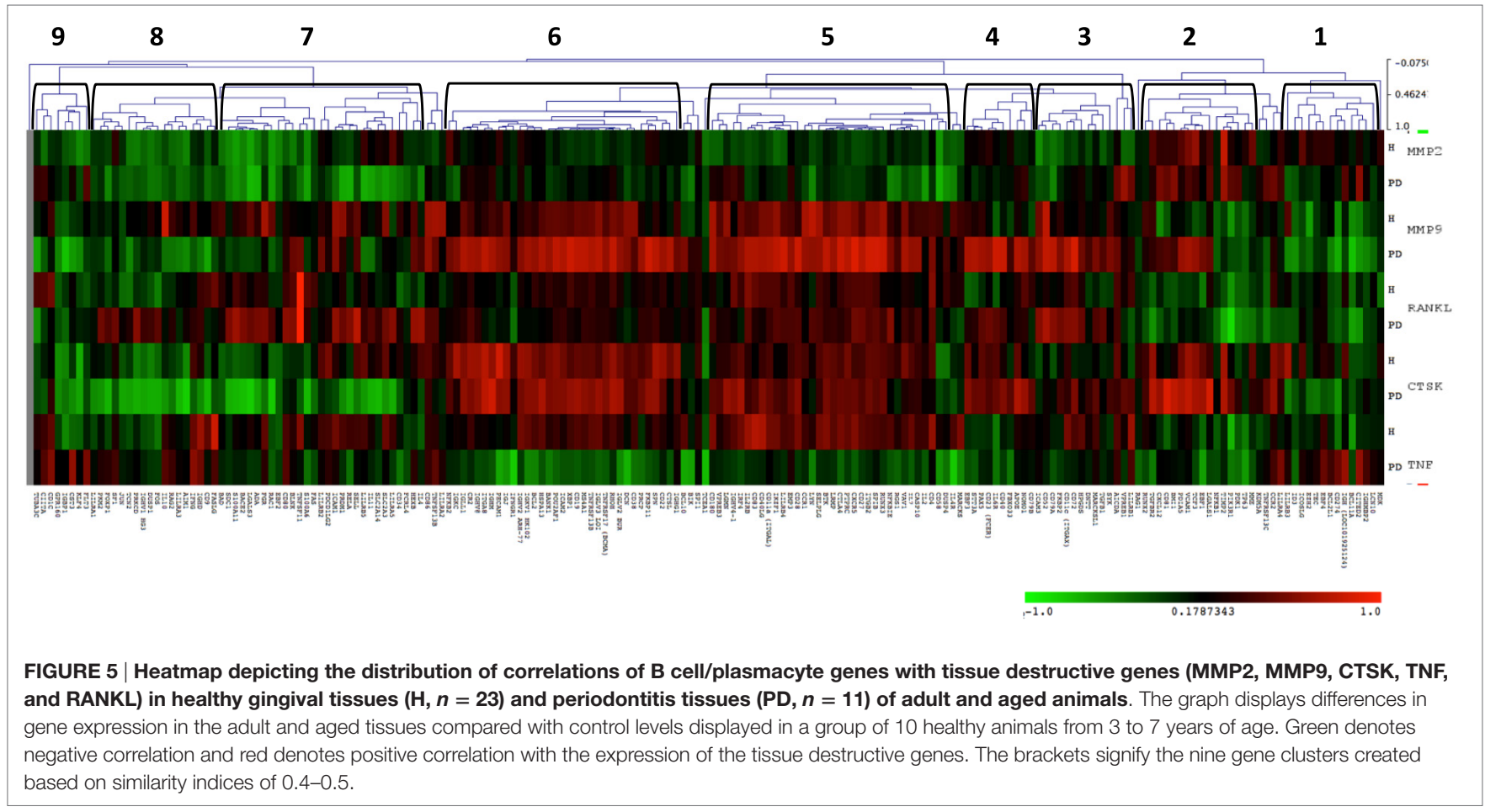

TABLE 4 | Functional categories of genes in the various clusters of response profiles related to expression of a set of tissue destructive genes (TDGs).

\begin{tabular}{|c|c|c|c|c|c|c|c|}
\hline \multirow[t]{2}{*}{ Cluster } & \multirow[t]{2}{*}{ TDG profile ${ }^{a}$} & \multicolumn{6}{|c|}{ Gene functional category } \\
\hline & & Ag-dep. activation & Act. & Prolif. & Diff./Mat. & Plasmacyte & Multiple fxn \\
\hline 1 & $\downarrow 9 ; \uparrow \top$ & $4(3)^{b}$ & $1(1)$ & $2(3)$ & $4(5)$ & $3(2)$ & $1(1)$ \\
\hline 2 & $\begin{array}{l}\uparrow 2 ; \uparrow C \\
\text { PD: } \uparrow 9\end{array}$ & $0(2)$ & $1(1)$ & $3(2)$ & $4(4)$ & $2(1)$ & $2(1)$ \\
\hline 3 & $\begin{array}{l}\mathrm{PD}: \uparrow 9 ; \uparrow C ; \uparrow R \\
\mathrm{H}: \downarrow 2\end{array}$ & $4(3)$ & $2(1)$ & $2(2)$ & $6(4)$ & $0(2)$ & $0(1)$ \\
\hline 4 & PD: $\uparrow 9 ; \uparrow C$ & $1(2)$ & $0(1)$ & $0(2)$ & $4(3)$ & $2(1)$ & $3(1)$ \\
\hline 5 & $\begin{array}{l}\uparrow 9 ; \uparrow C ; \uparrow R \\
H: \uparrow T\end{array}$ & $8(7)$ & $3(3)$ & $6(6)$ & $8(11)$ & $4(4)$ & $5(2)$ \\
\hline 6 & $\uparrow 9 ; \uparrow C ; \downarrow \top$ & $7(7)$ & $6(3)$ & $6(6)$ & $10(11)$ & $3(4)$ & $2(2)$ \\
\hline 7 & $\downarrow 2 ; \uparrow R ; \downarrow C$ & $5(6)$ & $1(3)$ & $5(5)$ & $10(9)$ & $5(4)$ & $4(2)$ \\
\hline 8 & $\begin{array}{l}\downarrow 2 ; \downarrow C \\
\text { PD: } \downarrow 9\end{array}$ & $5(4)$ & $2(2)$ & $2(3)$ & $5(6)$ & $3(3)$ & $1(1)$ \\
\hline 9 & $\begin{array}{l}\downarrow C \\
P D: \downarrow 9 ; \uparrow \top \\
H: \downarrow 2\end{array}$ & $3(2)$ & $\begin{array}{l}0 \\
(1)\end{array}$ & $3(1)$ & $1(3)$ & $1(1)$ & $0(1)$ \\
\hline
\end{tabular}

aTDG profile denotes $\uparrow$, positive correlation; $\downarrow$, negative correlation; 2 - MMP2; 9 - MMP9; C - CTSK; R - RANKL; T - TNF $\alpha$. H denotes only in healthy tissues, and PD denotes only in periodontitis tissues.

${ }^{b}$ Numbers denote frequency of genes observed in individual clusters and number of genes expected based on total genes representing that function (parentheses).

Those highlighted in bold indicate altered distribution.

the potential for various hypersensitivity reactions that could contribute to local tissue destruction. There is also a wealth of literature supporting the existence of local specific antibody production by plasma cells present in inflamed tissues of the periodontal pocket because levels of local antibody can be significantly greater than those in the serum $(19,58,59)$. However, the conundrum of existing data is why there appears to be a coincidence of chronic oral infection with accompanying periods of exacerbated disease and an active, often substantial specific local and systemic immune response in periodontitis $(19,22)$. At present, with our current level of knowledge, the true significance and function of the adaptive immune response under normal circumstances remains to be elucidated, let alone how aging specifically modulates the effectiveness of these responses.

Numerous alterations in B cells occur with aging (60-62). A critical aspect of B-lymphocytes is the heterogeneity of the 
stimulated mature plasmacytes differing in terms of the antigenic specificity of their resulting antibody-combining sites. Dunn-Walters and Ademokun (63) have suggested that one consequence of aging effects on the humoral immune system is an altered B-cell diversity; however, how this process occurs which remains unclear. Various studies have identified possible differences in lymphocyte subpopulations across the lifespan that has been proposed to contribute to the onset of age-related variations of the adaptive immune responses (64-66), such that the in situ environments in old age are considered to be (1) reduced in B-cell generation and (2) altered in the readout of the antibody repertoire. Riley (64) has suggested that in old age B cell development may progressively be diverted into a pre-BCR compromised pathway. While substantial literature is available over the last 40 years documenting levels of serum, gingival crevicular fluid, and salivary antibody to oral bacteria as they relate to periodontitis $(19,22)$, evidence is sparse regarding how these antibody responses are regulated with aging (22). However, early studies of these responses that implied an increase in antibody levels with age, really did not effectively distinguish the effect of aging directly on the immune response system versus response profiles that reflected increased extent and severity of periodontitis, e.g., oral infection, with aging (67).

The prevalence and severity of periodontitis, including missing teeth, increase significantly with age in various species of non-human primates $(49,68,69)$, and the disease is associated with antibody responses in this animal model to a battery of oral bacteria, including periodontal pathogens (49). We have evaluated various aspects of cellular gene expression that would contribute to adaptive immune responses in gingival tissues using this non-human primate model of periodontitis, including antigenpresenting cells (70-72), characteristics of macrophage footprints in healthy and periodontitis gingival tissues from animals across their lifespan, as well as plasticity of the macrophage population in gingival tissues (73), and related to T cell phenotype/function during the initiation and progression of periodontitis related these to the expression of soft and bone tissue destruction genes (74).

This study extended these findings to the level of B cells and plasmacyte gene expression profiles with aging and periodontitis in this human-like animal disease model. While substantial research has developed focusing on innate immune and inflammatory molecular mechanisms of periodontitis $(28,57,75,76)$, we observed that within the upregulated transcriptome of both humans and non-human primates with periodontitis $40-60 \%$ of these genes were related to adaptive immune responses. These findings defined that, in fact, we still have a substantial gap in understanding the molecular events of adaptive immunity occurring in diseased gingiva that must play a critical role in the progression and/or resolution of the disease. Evaluation of transcriptomic footprints of B cells and plasmacytes provided a new view of patterns in healthy aging. First, a number of genes associated with the function of these cells were upregulated in healthy aged tissues, whereas an increased number of genes were significantly downregulated in healthy tissues from younger animals. These altered genes were primarily associated with what would be predicted to be an upregulation of B cell activation, proliferation, and differentiation/maturation processes occurring in the healthy aged tissues. Approximately $1 / 3$ of the B cell/ plasmacyte genes in healthy tissues were positively correlated with MMP9 expression levels across all of the functional classes of the B cell/plasmacyte genes, and approximately $1 / 2$ of the genes in periodontitis were positively correlated with expression of this tissue altering enzyme. Results with CTSK responses showed a similar prevalence of positive correlations in healthy and periodontitis tissues, while a cluster of genes were negatively correlated with CTSK primarily in the periodontitis tissues. The patterns of responses related to RANKL showed that three of the clusters of B cell genes were generally positively correlated with RANKL, while only Cluster 5 was positively correlated in healthy tissues. High numbers of B cell/plasmacyte genes were also positively correlated with TNF $\alpha$ responses in the healthy tissues, focusing the most elevated levels in antigen-dependent activation genes. Summarizing these findings supported that increased B cell-related gene changes are observed in healthy aging tissues and that in healthy tissues (irrespective of age), generally B cell/ plasmacyte-associated gene expression positively correlated with levels of expression of various tissue destructive biomolecules. An interpretation of these findings is that with healthy aging an increase in tissue destructive gene expression, as we have recently reported (77), is balanced by an active B cell-related response profile that enhances the likelihood of maintaining homeostasis of these mucosal tissues even with the overall impact of aging on the immune response system.

These findings contrasted with periodontitis tissues where upregulated genes in aging periodontitis tissues were often two times greater than the level expressed in adult periodontitis, with nearly complete overlap. Approximately $40-60 \%$ of the antigendependent activation, B cell activation, B cell proliferation, and $\mathrm{B}$ cell differentiation/maturation genes were altered with periodontitis, generally being increased in both adults and aged animals. Numerous genes related to immunoglobulin heavy and light change rearrangement and production (IGHG1, IGHM, IGHV2, IGHV3, IGHV4, IGJ, IGKC, IGKV1, IGLV2, IGLV3, and IGLL1) were substantially upregulated with the highest fold increases in aged animals with periodontitis. Additionally, complement receptor 2 (CR2, Epstein-Barr virus receptor, CD21), POU domain class 2-associating factor 1 (POU2AF1), and TNFRSF17 [B-cell maturation antigen (BCMA); tumor necrosis factor receptor superfamily member 17] were increased in aged periodontitis approximately 10 -fold compared with healthy adult tissues. CR2 is on mature B cells and engages with membrane associated CD19 and CD81 leading to a complex called the B cell coreceptor complex (78-80). CR2 binds to antigens through attached C3d when the B cell membrane IgM binds to specific antigen. This antigen-specific binding results in $\mathrm{B}$ cells having a substantially elevated response to the antigen and, thus, enabling the complement system to play a role in B-cell activation and maturation. POU2AF1 codes for a transcriptional coactivator, Obf1 (Bob.1) that specifically associates with either OCT1 (POU2F1) or OCT2 (POU2F2). It functions as a critical factor to accentuate OCT1- and OCT2-mediated promoter activation of immunoglobulin gene expression (81-83). It is essential, as part of the B cell receptor signaling pathway, for the response of B-cells 
to antigens and required for the formation of germinal centers $(84,85)$. TNFRSF17 is a member of the TNF receptor superfamily and binds $\mathrm{B}$ cell activating factor (BAFF; TNFSF13B), which is expressed in $\mathrm{B}$ lineage cells resulting in potent $\mathrm{B}$ cell activation, as well as NF- $\kappa B$ and MAPK8/JNK activation $(86,87)$. It is preferentially expressed on mature $\mathrm{B}$ cells and ligand engagement contributes to proliferation and differentiation of the B cells (78, 88). This receptor also binds to various TRAF family members (TNF receptor-associated factors) that interact with inhibitorof-apoptosis proteins (IAPs) driving anti-apoptotic signals contributing to cell survival and proliferation $(89,90)$. These biomolecules and their associated pathways may provide novel targets for better understanding of the local adaptive immune response to the microbial insult that occurs with periodontitis.

Various discussions regarding the role of adaptive immunity, and particularly humoral immune responses in the development or protection from periodontitis have occurred over the decades, with some consistency in findings regarding antibody levels being increased with disease (22). However, a summation of the available literature from human studies regarding aging effects on humoral immune responses to oral microorganisms suggests rather minimal evidence to either support or refute that aging directly affects the capacity of individuals to mount an adaptive immune response to bacteria comprising the autochthonous oral microbiome including those associated with periodontitis. This report describes studies that emphasize a rather extensive alteration in the gingival environment with regard to B cell and plasmacyte activities in this non-human primate model of periodontitis and suggest changes that occur in healthy tissues, with aging, as well as extensive alterations associated with naturally occurring disease. How these responses are driven by changes in the microbiome of subgingival biofilms with disease and processes that may occur with adaptive immune responses to control the infection and reestablish homeostasis remains to be determined.

\section{REFERENCES}

1. Taverna G, Seveso M, Giusti G, Hurle R, Graziotti P, Stifter S, et al. Senescent remodeling of the innate and adaptive immune system in the elderly men with prostate cancer. Curr Gerontol Geriatr Res (2014) 2014:478126. doi: $10.1155 / 2014 / 478126$

2. O'Connor JE, Herrera G, Martinez-Romero A, de Oyanguren FS, Diaz L, Gomes A, et al. Systems biology and immune aging. Immunol Lett (2014) 162(1 Pt B):334-45. doi:10.1016/j.imlet.2014.09.009

3. Mabbott NA, Kobayashi A, Sehgal A, Bradford BM, Pattison M, Donaldson DS. Aging and the mucosal immune system in the intestine. Biogerontology (2015) 16(2):133-45. doi:10.1007/s10522-014-9498-Z

4. Grubeck-Loebenstein B, Della Bella S, Iorio AM, Michel JP, Pawelec G, Solana R. Immunosenescence and vaccine failure in the elderly. Aging Clin Exp Res (2009) 21(3):201-9. doi:10.1007/BF03324904

5. Castelo-Branco C, Soveral I. The immune system and aging: a review. Gynecol Endocrinol (2014) 30(1):16-22. doi:10.3109/09513 590.2013 .852531

6. Franceschi C, Campisi J. Chronic inflammation (inflammaging) and its potential contribution to age-associated diseases. J Gerontol A Biol Sci Med Sci (2014) 69(Suppl 1):S4-9. doi:10.1093/gerona/glu057

7. Margolis L. Immunoactivation at the crossroads of human disease. Am J Med (2015) 128(6):562-6. doi:10.1016/j.amjmed.2014.12.026

8. Boraschi D, Aguado MT, Dutel C, Goronzy J, Louis J, Grubeck-Loebenstein B, et al. The gracefully aging immune system. Sci Transl Med (2013) 5(185):185s8. doi:10.1126/scitranslmed.3005624

\section{AUTHOR CONTRIBUTIONS}

JE contributed to the experimental design and study activities, and also spearheaded the preparation of the manuscript and interpretation of the data. SK supported the preparation of the samples and interface with the core facility for microarray analysis. MN contributed to the experimental design and study activities, and also reviewed and contributed to content of the manuscript. LO supported the clinical aspects of evaluation and sample collection. JM provided support for conduct of the study and evaluation of the animals included in the experiment. LC provided human clinical specimens and reviewed the manuscript. MT provided human clinical specimens and contributed to discussion of the results. AS provided biostatistical support for the gene expression analyses. SP provided support for generation of the heatmap figures and interpretation of the results. OG responsible for the experimental design and oversight of the conduct of the study, and also contributed to content of the manuscript and review of the data.

\section{ACKNOWLEDGMENTS}

The authors thank Dr. K. C. Chen and the support of the University of Kentucky Microarray Core personnel. The authors express our gratitude to staff at Caribbean Primate Research Center for their invaluable technical assistance. This work was supported by USPHS grants P20RR020145, P20GM103538, P40RR03640, and UL1TR000117 from the National Institutes of Health.

\section{SUPPLEMENTARY MATERIAL}

The Supplementary Material for this article can be found online at http://journal.frontiersin.org/article/10.3389/fimmu.2016.00272

9. Liang S, Hosur KB, Domon H, Hajishengallis G. Periodontal inflammation and bone loss in aged mice. J Periodontal Res (2010) 45(4):574-8. doi:10.1111/j.1600-0765.2009.01245.x

10. Bullon P, Battino M, Varela-Lopez A, Perez-Lopez P, Granados-Principal S, RamirezTortosa MC, et al. Diets based on virgin olive oil or fish oil but not on sunflower oil prevent age-related alveolar bone resorption by mitochondrial-related mechanisms. PLoS One (2013) 8(9):e74234. doi:10.1371/journal.pone.0074234

11. Arai K, Tanaka S, Yamamoto-Sawamura T, Sone K, Miyaishi O, Sumi Y. Aging changes in the periodontal bone of F344/N rat. Arch Gerontol Geriatr (2005) 40(3):225-9. doi:10.1016/j.archger.2004.08.005

12. Lam RS, O’Brien-Simpson NM, Hamilton JA, Lenzo JC, Holden JA, Brammar GC, et al. GM-CSF and uPA are required for Porphyromonas gingivalis-induced alveolar bone loss in a mouse periodontitis model. Immunol Cell Biol (2015) 93(8):705-15. doi:10.1038/icb.2015.25

13. Kim PD, Xia-Juan X, Crump KE, Abe T, Hajishengallis G, Sahingur SE. Toll-like receptor 9-mediated inflammation triggers alveolar bone loss in experimental murine periodontitis. Infect Immun (2015) 83(7):2992-3002. doi:10.1128/IAI.00424-15

14. Araujo-Pires AC, Vieira AE, Francisconi CF, Biguetti CC, Glowacki A, Yoshizawa S, et al. IL-4/CCL22/CCR4 axis controls regulatory T-cell migration that suppresses inflammatory bone loss in murine experimental periodontitis. J Bone Miner Res (2015) 30(3):412-22. doi:10.1002/jbmr.2376

15. Jiao Y, Darzi Y, Tawaratsumida K, Marchesan JT, Hasegawa M, Moon H, et al. Induction of bone loss by pathobiont-mediated Nod1 signaling in the oral cavity. Cell Host Microbe (2013) 13(5):595-601. doi:10.1016/j. chom.2013.04.005 
16. Graves DT, Kang J, Andriankaja O, Wada K, Rossa C Jr. Animal models to study host-bacteria interactions involved in periodontitis. Front Oral Biol (2012) 15:117-32. doi:10.1159/000329675

17. Franceschi C, Valensin S, Bonafè M, Paolisso G, Yashin AI, Monti D, De Benedictis G. The network and the remodeling theories of aging: historical background and new perspectives. Exp Gerontol (2000) 35(6-7):879-96. doi:10.1016/S0531-5565(00)00172-8

18. Hajishengallis G. Periodontitis: from microbial immune subversion to systemic inflammation. Nat Rev Immunol (2015) 15(1):30-44. doi:10.1038/ nri3785

19. Ebersole JL. Humoral immune responses in gingival crevice fluid: local and systemic implications. Periodontol 2000 (2003) 31:135-66. doi:10.1034/j.1600-0757.2003.03109.x

20. Ebersole JL, Cappelli D, Holt SC. Periodontal diseases: to protect or not to protect is the question? Acta Odontol Scand (2001) 59(3):161-6. doi:10.1080/000163501750266756

21. Kinane DF, Mooney J, Ebersole JL. Humoral immune response to Actinobacillus actinomycetemcomitans and Porphyromonas gingivalis in periodontal disease. Periodontol 2000 (1999) 20:289-340. doi:10.1111/j.1600-0757.1999.tb00164.x

22. Ebersole JL, Dawson DR III, Morford LA, Peyyala R, Miller CS, Gonzalez OA. Periodontal disease immunology: 'double indemnity' in protecting the host. Periodontol 2000 (2013) 62(1):163-202. doi:10.1111/prd.12005

23. Kebschull M, Demmer RT, Grun B, Guarnieri P, Pavlidis P, Papapanou PN. Gingival tissue transcriptomes identify distinct periodontitis phenotypes. J Dent Res (2014) 93(5):459-68. doi:10.1177/0022034514527288

24. Kebschull M, Guarnieri P, Demmer RT, Boulesteix AL, Pavlidis P, Papapanou PN. Molecular differences between chronic and aggressive periodontitis. J Dent Res (2013) 92(12):1081-8. doi:10.1177/0022034513506011

25. Jonsson D, Ramberg P, Demmer RT, Kebschull M, Dahlen G, Papapanou PN. Gingival tissue transcriptomes in experimental gingivitis. J Clin Periodontol (2011) 38(7):599-611. doi:10.1111/j.1600-051X.2011.01719.x

26. Kebschull M, Papapanou PN. The use of gene arrays in deciphering the pathobiology of periodontal diseases. Methods Mol Biol (2010) 666:385-93. doi:10.1007/978-1-60761-820-1_24

27. Demmer RT, Behle JH, Wolf DL, Handfield M, Kebschull M, Celenti R, et al. Transcriptomes in healthy and diseased gingival tissues. J Periodontol (2008) 79(11):2112-24. doi:10.1902/jop.2008.080139

28. Ji S, Choi Y. Innate immune response to oral bacteria and the immune evasive characteristics of periodontal pathogens. J Periodontal Implant Sci (2013) 43(1):3-11. doi:10.5051/jpis.2013.43.1.3

29. Zelkha SA, Freilich RW, Amar S. Periodontal innate immune mechanisms relevant to atherosclerosis and obesity. Periodontol 2000 (2010) 54(1):207-21. doi:10.1111/j.1600-0757.2010.00358.x

30. Graves D. Cytokines that promote periodontal tissue destruction. J Periodontol (2008) 79(8 Suppl):1585-91. doi:10.1902/jop.2008.080183

31. Gibson FC III, Ukai T, Genco CA. Engagement of specific innate immune signaling pathways during Porphyromonas gingivalis induced chronic inflammation and atherosclerosis. Front Biosci (2008) 13:2041-59. doi:10.2741/2822

32. Hwang AM, Stoupel J, Celenti R, Demmer RT, Papapanou PN. Serum antibody responses to periodontal microbiota in chronic and aggressive periodontitis: a postulate revisited. J Periodontol (2014) 85(4):592-600. doi:10.1902/jop.2013.130172

33. Takeuchi Y, Aramaki M, Nagasawa T, Umeda M, Oda S, Ishikawa I. Immunoglobulin G subclass antibody profiles in Porphyromonas gingivalis-associated aggressive and chronic periodontitis patients. Oral Microbiol Immunol (2006) 21(5):314-8. doi:10.1111/j.1399-302X.2006.00296.X

34. Wang D, Kawashima Y, Nagasawa T, Takeuchi Y, Kojima T, Umeda M, et al. Elevated serum IgG titer and avidity to Actinobacillus actinomycetemcomitans serotype c in Japanese periodontitis patients. Oral Microbiol Immunol (2005) 20(3):172-9. doi:10.1111/j.1399-302X.2005.00208.x

35. Califano JV, Schifferle RE, Gunsolley JC, Best AM, Schenkein HA, Tew JG. Antibody reactive with Porphyromonas gingivalis serotypes K1-6 in adult and generalized early-onset periodontitis. J Periodontol (1999) 70(7):730-5. doi:10.1902/jop.1999.70.7.730

36. Ebersole JL, Taubman MA, Smith DJ, Haffajee AD. Effect of subgingival scaling on systemic antibody responses to oral microorganisms. Infect Immun (1985) 48(2):534-9.

37. Yamazaki K, Ueki-Maruayama K, Honda T, Nakajima T, Seymour GJ. Effect of periodontal treatment on the serum antibody levels to heat shock proteins. Clin Exp Immunol (2004) 135(3):478-82. doi:10.1111/j.1365-2249.2003.02375.x
38. Sakai Y, Shimauchi H, Ito HO, Kitamura M, Okada H. Porphyromonas gingivalis-specific IgG subclass antibody levels as immunological risk indicators of periodontal bone loss. J Clin Periodontol (2001) 28(9):853-9. doi:10.1034/j.1600-051x.2001.028009853.x

39. Beikler T, Karch H, Ehmke B, Klaiber B, Flemmig TF. Protective effect of serum antibodies against a 110-kilodalton protein of Actinobacillus actinomycetemcomitans following periodontal therapy. Oral Microbiol Immunol (1999) 14(5):281-7. doi:10.1034/j.1399-302X.1999.140503.x

40. Mooney J, Adonogianaki E, Riggio MP, Takahashi K, Haerian A, Kinane DF. Initial serum antibody titer to Porphyromonas gingivalis influences development of antibody avidity and success of therapy for chronic periodontitis. Infect Immun (1995) 63(9):3411-6.

41. Taubman MA, Kawai T, Han X. The new concept of periodontal disease pathogenesis requires new and novel therapeutic strategies. J Clin Periodontol (2007) 34(5):367-9. doi:10.1111/j.1600-051X.2007.01065.x

42. Kawai T, Matsuyama T, Hosokawa Y, Makihira S, Seki M, Karimbux NY, et al. B and T lymphocytes are the primary sources of RANKL in the bone resorptive lesion of periodontal disease. Am J Pathol (2006) 169(3):987-98. doi:10.2353/ajpath.2006.060180

43. Taubman MA, Valverde P, Han X, Kawai T. Immune response: the key to bone resorption in periodontal disease. J Periodontol (2005) 76(11 Suppl):2033-41. doi:10.1902/jop.2005.76.11-S.2033

44. Zhu C, Yang J, Sun J, Shi J, Gou J, Li A. Induction of immune response and prevention of alveolar bone loss with recombinant Porphyromonas gingivalis peptidylarginine deiminase. Arch Oral Biol (2013) 58(12):1777-83. doi:10.1016/j.archoralbio.2013.09.006

45. Polak D, Wilensky A, Shapira L, Weiss EI, Houri-Haddad Y. Vaccination of mice with Porphyromonas gingivalis or Fusobacterium nucleatum modulates the inflammatory response, but fails to prevent experimental periodontitis. J Clin Periodontol (2010) 37(9):812-7. doi:10.1111/j.1600-051X.2010.01598.x

46. Persson GR. Immune responses and vaccination against periodontal infections. JClin Periodontol (2005) 32(Suppl 6):39-53. doi:10.1111/j.1600-051X.2005.00800.x

47. Ebersole JL, Brunsvold M, Steffensen B, Wood R, Holt SC. Effects of immunization with Porphyromonas gingivalis and Prevotella intermedia on progression of ligature-induced periodontitis in the nonhuman primate Macaca fascicularis. Infect Immun (1991) 59(10):3351-9.

48. Gonzalez OA, Stromberg AJ, Huggins PM, Gonzalez-Martinez J, Novak MJ, Ebersole JL. Apoptotic genes are differentially expressed in aged gingival tissue. J Dent Res (2011) 90(7):880-6. doi:10.1177/0022034511403744

49. Ebersole JL, Steffen MJ, Gonzalez-Martinez J, Novak MJ. Effects of age and oral disease on systemic inflammatory and immune parameters in nonhuman primates. Clin Vaccine Immunol (2008) 15(7):1067-75. doi:10.1128/CVI.00258-07

50. Meka A, Bakthavatchalu V, Sathishkumar S, Lopez MC, Verma RK, Wallet SM, et al. Porphyromonas gingivalis infection-induced tissue and bone transcriptional profiles. Mol Oral Microbiol (2010) 25(1):61-74. doi:10.1111/j.2041-1014.2009.00555.x

51. Li W. Volcano plots in analyzing differential expressions with mRNA microarrays. J Bioinform Comput Biol (2012) 10(6):1231003. doi:10.1142/ S0219720012310038

52. Podmore M, Ebersole JL, Kinane DF. Immunodominant antigens in periodontal disease: a real or illusive concept? Crit Rev Oral Biol Med (2001) 12(2):179-85. doi:10.1177/10454411010120020701

53. Shaw AC, Goldstein DR, Montgomery RR. Age-dependent dysregulation of innate immunity. Nat Rev Immunol (2013) 13(12):875-87. doi:10.1038/ nri3547

54. Qian F, Wang X, Zhang L, Chen S, Piecychna M, Allore H, et al. Age-associated elevation in TLR5 leads to increased inflammatory responses in the elderly. Aging Cell (2012) 11(1):104-10. doi:10.1111/j.1474-9726.2011.00759.x

55. Shaw AC, Panda A, Joshi SR, Qian F, Allore HG, Montgomery RR. Dysregulation of human toll-like receptor function in aging. Ageing Res Rev (2011) 10(3):346-53. doi:10.1016/j.arr.2010.10.007

56. Huttner EA, Machado DC, de Oliveira RB, Antunes AG, Hebling E. Effects of human aging on periodontal tissues. Spec Care Dentist (2009) 29(4):149-55. doi:10.1111/j.1754-4505.2009.00082.x

57. Hajishengallis G. Aging and its impact on innate immunity and inflammation: implications for periodontitis. J Oral Biosci (2014) 56(1):30-7. doi:10.1016/j. job.2013.09.001

58. Lamster IB, Celenti R, Ebersole JL. The relationship of serum IgG antibody titers to periodontal pathogens to indicators of the host response in crevicular fluid. 
J Clin Periodontol (1990) 17(7 Pt 1):419-25. doi:10.1111/j.1600-051X.1990. tb02340.x

59. Yucel-Lindberg T, Bage T. Inflammatory mediators in the pathogenesis of periodontitis. Expert Rev Mol Med (2013) 15:e7. doi:10.1017/erm.2013.8

60. Blomberg BB, Frasca D. Age effects on mouse and human B cells. Immunol Res (2013) 57(1-3):354-60. doi:10.1007/s12026-013-8440-9

61. Frasca D, Diaz A, Romero M, Landin AM, Blomberg BB. Age effects on B cells and humoral immunity in humans. Ageing Res Rev (2011) 10(3):330-5. doi:10.1016/j.arr.2010.08.004

62. Frasca D, Blomberg BB. Aging affects human B cell responses. J Clin Immunol (2011) 31(3):430-5. doi:10.1007/s10875-010-9501-7

63. Dunn-Walters DK, Ademokun AA. B cell repertoire and ageing. Curr Opin Immunol (2010) 22(4):514-20. doi:10.1016/j.coi.2010.04.009

64. Riley RL. Impaired B lymphopoiesis in old age: a role for inflammatory B cells? Immunol Res (2013) 57(1-3):361-9. doi:10.1007/s12026-013-8444-5

65. Frasca D, Blomberg BB. Aging impairs murine B cell differentiation and function in primary and secondary lymphoid tissues. Aging Dis (2011) 2(5):361-73.

66. Mazzoccoli G, Vendemiale G, De Cata A, Tarquini R. Change of gammadeltaTCR-expressing $\mathrm{T}$ cells in healthy aging. Int J Immunopathol Pharmacol (2011) 24(1):201-9.

67. Mouton C, Hammond PG, Slots J, Genco RJ. Serum antibodies to oral Bacteroides asaccharolyticus (Bacteroides gingivalis): relationship to age and periondontal disease. Infect Immun (1981) 31(1):182-92.

68. Schou S, Holmstrup P, Kornman KS. Non-human primates used in studies of periodontal disease pathogenesis: a review of the literature. J Periodontol (1993) 64(6):497-508. doi:10.1902/jop.1993.64.6.497

69. Miller DR, Aufdemorte TB, Fox WC, Waldrop TC, Mealey BL, Brunsvold MA. Periodontitis in the baboon: a potential model for human disease. J Periodontal Res (1995) 30(6):404-9. doi:10.1111/j.1600-0765.1995.tb01294.x

70. Wong $C$, Goldstein DR. Impact of aging on antigen presentation cell function of dendritic cells. Curr Opin Immunol (2013) 25(4):535-41. doi:10.1016/j. coi.2013.05.016

71. Makala LH, Nishikawa Y, Suzuki N, Nagasawa H. Immunology. Antigenpresenting cells in the gut. J Biomed Sci (2004) 11(2):130-41. doi:10.1007/ BF02256556

72. Cutler CW, Teng YT. Oral mucosal dendritic cells and periodontitis: many sides of the same coin with new twists. Periodontol 2000 (2007) 45:35-50. doi:10.1111/j.1600-0757.2007.00222.x

73. Gonzalez OA, Novak MJ, Kirakodu S, Stromberg A, Nagarajan R, Huang CB, et al. Differential gene expression profiles reflecting macrophage polarization in aging and periodontitis gingival tissues. Immunol Invest (2015) 44(7):643-64. doi:10.3109/08820139.2015.1070269

74. Ebersole JL, Kirakodu S, Novak MJ, Stromberg AJ, Shen S, Orraca L, et al. Cytokine gene expression profiles during initiation, progression and resolution of periodontitis. J Clin Periodontol (2014) 41(9):853-61. doi:10.1111/ jcpe. 12286

75. Hajishengallis G. Immunomicrobial pathogenesis of periodontitis: keystones, pathobionts, and host response. Trends Immunol (2014) 35(1):3-11. doi:10.1016/j.it.2013.09.001

76. Benakanakere M, Kinane DF. Innate cellular responses to the periodontal biofilm. Front Oral Biol (2012) 15:41-55. doi:10.1159/000329670

77. Pandruvada SN, Gonzalez OA, Kirakodu S, Gudhimella S, Stromberg AJ, Ebersole JL, et al. Bone biology-related gingival transcriptome in aging and periodontitis in non-human primates. J Clin Periodontol (2016) 43(5):408-17. doi:10.1111/jcpe. 12528
78. Hoehn KB, Fowler A, Lunter G, Pybus OG. The diversity and molecular evolution of B-cell receptors during infection. Mol Biol Evol (2016) 33(5):1147-57. doi:10.1093/molbev/msw015

79. Barrington RA, Schneider TJ, Pitcher LA, Mempel TR, Ma M, Barteneva NS, et al. Uncoupling CD21 and CD19 of the B-cell coreceptor. Proc Natl Acad Sci U S A (2009) 106(34):14490-5. doi:10.1073/pnas.0903477106

80. Barrington RA, Zhang M, Zhong X, Jonsson H, Holodick N, Cherukuri A, et al. CD21/CD19 coreceptor signaling promotes B cell survival during primary immune responses. J Immunol (2005) 175(5):2859-67. doi:10.4049/ jimmunol.175.5.2859

81. Corcoran L, Emslie D, Kratina T, Shi W, Hirsch S, Taubenheim N, et al. Oct2 and Obf1 as facilitators of B:T cell collaboration during a humoral immune response. Front Immunol (2014) 5:108. doi:10.3389/fimmu.2014.00108

82. Emslie D, D'Costa K, Hasbold J, Metcalf D, Takatsu K, Hodgkin PO, et al. Oct2 enhances antibody-secreting cell differentiation through regulation of IL-5 receptor alpha chain expression on activated B cells. J Exp Med (2008) 205(2):409-21. doi:10.1084/jem.20072049

83. Ochiai K, Maienschein-Cline M, Simonetti G, Chen J, Rosenthal R, Brink R, et al. Transcriptional regulation of germinal center B and plasma cell fates by dynamical control of IRF4. Immunity (2013) 38(5):918-29. doi:10.1016/j. immuni.2013.04.009

84. Zhang Y, Garcia-Ibanez L, Toellner KM. Regulation of germinal center B-cell differentiation. Immunol Rev (2016) 270(1):8-19. doi:10.1111/ imr. 12396

85. Goenka R, Scholz JL, Sindhava VJ, Cancro MP. New roles for the BLyS/BAFF family in antigen-experienced B cell niches. Cytokine Growth Factor Rev (2014) 25(2):107-13. doi:10.1016/j.cytogfr.2014.01.001

86. Shen X, Guo Y, Qi J, Shi W, Wu X, Ju S. Binding of B-cell maturation antigen to B-cell activating factor induces survival of multiple myeloma cells by activating Akt and JNK signaling pathways. Cell Biochem Funct (2016) 34(2):104-10. doi:10.1002/cbf.3169

87. Zhao C, Inoue J, Imoto I, Otsuki T, Iida S, Ueda R, et al. POU2AF1, an amplification target at $11 \mathrm{q} 23$, promotes growth of multiple myeloma cells by directly regulating expression of a B-cell maturation factor, TNFRSF17. Oncogene (2008) 27(1):63-75. doi:10.1038/sj.onc.1210637

88. Yu G, Boone T, Delaney J, Hawkins N, Kelley M, Ramakrishnan M, et al. APRIL and TALL-I and receptors BCMA and TACI: system for regulating humoral immunity. Nat Immunol (2000) 1(3):252-6. doi:10.1038/79802

89. Melchers F. Checkpoints that control B cell development. J Clin Invest (2015) 125(6):2203-10. doi:10.1172/JCI78083

90. Bossen C, Schneider P. BAFF, APRIL and their receptors: structure, function and signaling. Semin Immunol (2006) 18(5):263-75. doi:10.1016/j. smim.2006.04.006

Conflict of Interest Statement: The authors declare that the research was conducted in the absence of any commercial or financial relationships that could be construed as a potential conflict of interest.

Copyright (c) 2016 Ebersole, Kirakodu, Novak, Orraca, Martinez, Cunningham, Thomas, Stromberg, Pandruvada and Gonzalez. This is an open-access article distributed under the terms of the Creative Commons Attribution License (CC BY). The use, distribution or reproduction in other forums is permitted, provided the original author(s) or licensor are credited and that the original publication in this journal is cited, in accordance with accepted academic practice. No use, distribution or reproduction is permitted which does not comply with these terms. 